\title{
Ensino de Física e Educação Especial: análise da interação entre professores de Física e professores da Educação Especial
}

\author{
Physics Teaching and Special Education: analysis of the interaction \\ between physics teachers and special education teachers
}

\author{
Alessandra Peixe (sanda.peixe@ hotmail.com) \\ Universidade Federal de Santa Catarina -UFSC \\ André Ary Leonel (andre.leonel@ufsc.br) \\ Universidade Federal de Santa Catarina -UFSC
}

\begin{abstract}
Resumo: A Educação Especial é uma área que vem se destacando e gerando grandes discussões em âmbito nacional, e o presente trabalho procura contribuir com tais discussões ao analisar a inclusão no ensino de Física em turmas com alunos do públicoalvo da Educação Especial do Colégio de Aplicação de uma Universidade Federal brasileira. Assume-se aqui o objetivo de compreender como a docência compartilhada acontece entre os professores de Física e os professores da Educação Especial. O campo de pesquisa é o Colégio de Aplicação da Universidade Federal, onde estes professores foram questionados acerca de como acontece a docência compartilhada entre eles. Optou-se pela metodologia de análise de conteúdo para a análise das asserções dos professores. Como fundamentação teórica foi realizada uma contextualização sobre Educação Especial no Brasil, e como o Colégio de Aplicação buscou se aperfeiçoar para que os alunos pudessem ser atendidos de forma adequada. Com as asserções nos questionários percebeu-se que o trabalho conjunto entre os professores está em processo, que existe uma preocupação em fazer o que for possível para que os alunos possam ser atendidos de maneira apropriada.
\end{abstract}

Palavras-chave: Educação Especial; Docência compartilhada; Ensino de Física inclusivo.

Abstract: Special Education is an area that has been standing out and generating great discussions at the national level, and the present work seeks to contribute to such discussions by analyzing the inclusion in Physics teaching in classes with Special Education students from The Application College of a Federal University Brazilian. The objective here is to understand how shared teaching happens between physics teachers and Special Education teachers. The research field is the College of Application of the Federal University, where these teachers were asked about how the teaching shared between them happens. We opted for the content analysis methodology for the analysis of teachers' assertions. As a theoretical foundation, a contextualization of Special Education in Brazil was carried out, and how the College of Application sought to improve itself so that students could be adequately served. With the assertions in the 
questionnaires, it was noticed that the joint work between teachers is in process, that there is a concern to do what is possible so that students can be properly served.

Keywords: Special Education; Shared teaching; Inclusive Physics Teaching.

\section{INTRODUÇÃO}

A área da Educação Especial vem ganhando destaque e notoriedade entre os meios, mas há tempos ela é discutida nas escolas e universidades. "No contexto atual, a inclusão escolar tornou-se uma máxima inquestionável e, por isso, os sistemas de ensino tencionam as escolas a envolverem seus professores, de tal forma, que é quase impossível se opor a ela" (RIGO, 2018, p. 3).

Acredita-se que há muito a ser melhorado, pois, mesmo com a inclusão da área nos currículos dos cursos de formação de professores, isso não tem sido suficiente para que os egressos destes cursos saiam preparados para trabalhar com alunos do públicoalvo da Educação Especial.

No ano de 2008, foi elaborada no Brasil a Política Nacional de Educação Especial na Perspectiva Inclusiva. Esta colaborou para que a Educação Especial tivesse mais visibilidade na educação brasileira. Com base nesta política, as escolas passaram a ter propostas pedagógicas que contemplavam a Educação Especial, onde foi definido como público-alvo os alunos com deficiência, Transtorno do Espectro Autista (TEA) e Altas Habilidades/Superdotação (AH/SD). A Educação Especial atua em conjunto com o ensino comum buscando atender as necessidades dos alunos do público-alvo (BRASIL, 2008).

Este artigo tem como objetivo investigar e analisar a promoção do ensino de Física inclusivo no Colégio de Aplicação de uma universidade federal, com foco na Educação Especial e compreender como a docência compartilhada acontece entre os professores de Física e os professores da Educação Especial nesta instituição de ensino. Para alcançar o objetivo optou-se pela aplicação de dois questionários com perguntas abertas e discursivas, um para os professores de Física e outro para os professores da Educação Especial. As respostas foram analisadas com base na metodologia de análise de conteúdo.

O objetivo dessa pesquisa foi entender e aferir como essa interação entre os professores contribui para o desenvolvimento de práticas de ensino-aprendizagem mais 
inclusivas. Espera-se que o processo de reflexão provocado pela elaboração das respostas às questões presentes no questionário, possa proporcionar um olhar mais crítico acerca das práticas desenvolvidas e, ao mesmo tempo, instigar a busca de novas práticas.

\section{EDUCAÇÃO ESPECIAL E INCLUSIVA}

A concepção da Educação Inclusiva tem ganhado mais espaço e um olhar mais voltado para sua total efetivação. Ela consiste em educação para todas as pessoas, mesmo aquelas que apresentam alguma dificuldade, tanto cognitiva, como de locomoção e também para as pessoas com deficiência, que não são aquelas que tem dificuldades de aprendizagem e nem de mobilidade reduzida. Muito se discute sobre a necessidade da Educação Inclusiva, mas atualmente, tem-se colocado em pauta a necessidade de vê-la em prática sem esquecer que não é algo pronto e acabado, mas que requer estudos, pesquisas, análises e aperfeiçoamentos.

No Brasil, a política de inclusão construída em 2008 vem trazendo mais destaque para essa área: "O movimento mundial pela inclusão é uma ação política, cultural, social e pedagógica, desencadeada em defesa do direito de todos os alunos de estarem juntos, aprendendo e participando, sem nenhum tipo de discriminação" (BRASIL, 2008, p. 5).

No Brasil, da chegada dos Jesuítas até por volta do final da década de 1940, a educação era um privilégio, ou seja, era exclusividade da elite que gozava de oportunidades e de uma educação de alta qualidade. Sem contar que as escolas e bibliotecas ficavam localizadas em centros urbanos, dificultando o acesso das classes menos abastadas. Mas, mesmo passando por várias mudanças, a educação não passou a ser completamente de todos e para todos. Quando se percebeu que esses estudantes precisavam de uma atenção a mais, optou-se por uma educação de modo substituto ao ensino regular.

A Educação Especial ao longo do tempo passou por um processo de transformação histórica e política, algumas conquistas foram alcançadas, mas muitos desafios foram enfrentados para a construção da sua história (SILVA et al, 2016; BRASIL, 2008). Para Mazzotta (1989, p. 39) Educação Especial é: 
[...] um conjunto de recursos e serviços educacionais especiais organizados para apoiar, suplementar e, em alguns casos, substituir os serviços educacionais comuns, para garantir a educação formal dos educandos que apresentam necessidades educacionais muito diferentes das da maioria das crianças e jovens.

A Política Nacional de Educação Especial na Perspectiva da Educação Inclusiva (2008) traz como conceito de Educação Inclusiva:

[...] um paradigma educacional fundamentado na concepção de direitos humanos, que conjuga igualdade e diferença como valores indissociáveis, e que avança em relação à idéia de equidade formal ao contextualizar as circunstâncias históricas da produção da exclusão dentro e fora da escola. (BRASIL, 2008, p. 5).

No início a Educação Especial e Inclusiva, mesmo sem a intenção, acabava sendo uma exclusão pois os alunos acabavam não entrando em uma sala regular. Por isso que atualmente busca-se inserir o aluno no ambiente regular junto aos seus pares (TANNÚS-VALADÃO; MENDES, 2018).

Com a proposta elaborada pelo MEC em 2008 buscou-se aumentar o suporte com atendimento educacional especializado para todas as etapas e modalidades da escola básica de forma a apoiar o desenvolvimento do estudante. Assim esse atendimento deve ser ofertado, de forma obrigatória (que nem sempre acontece), pelos sistemas de ensino, e realizado em contraturno do aluno nas escolas ou centro especializado (BRASIL, 2008).Para o atendimento desses alunos os professores devem ter em sua formação conhecimentos específicos da área de Educação Inclusiva, de modo que possam atuar de forma mais coerentes com esses alunos (BRASIL, 2008).

Para Camargo et al (2008, p. 02):

\begin{abstract}
A busca por uma "didática inclusiva" não é simples, deve respeitar e superar os modelos pedagógicos gerais enfatizando o impacto das variáveis específicas na implantação de uma educação para todos. Concluir que incluir alunos com deficiências em aulas de física, química, biologia, matemática, história, língua portuguesa, etc., deve ir além dos princípios gerais, e reconhecer a necessidade do investimento em pesquisas que revelem propriedades ativas das variáveis específicas.
\end{abstract}

Assim, a Educação Especial, na perspectiva da inclusão dos estudantes, vem ganhando espaço na educação regular. No Brasil, as escolas em sua grande maioria, possuem professores especializados na área, que buscam contribuir com o aprendizado do aluno. É necessário ter em mente que a Educação Especial busca atender o aluno de modo que este possa se sentir incluso em uma sala de aula regular. 


\section{a. EDUCAÇÃo ESPECIAL NO COLÉGIO DE APLICAÇÃo DE UMA UNIVERSIDADE FEDERAL}

A história do colégio de aplicação começa em 1961, com a criação de um campo de estágio destinado à prática docente dos alunos matriculados nos cursos de Didática (Geral e Específica) da Faculdade de Filosofia (FCF). Inicialmente era chamado de Ginásio de Aplicação. Primeiramente foi implantado a $1^{\mathrm{a}}$ série ginasial, e a cada ano, as séries subsequentes. Com o decorrer dos anos, o número de turmas por séries foi aumentando e em 1970 havia duas turmas por série. Neste mesmo ano o nome foi alterado de Ginásio de Aplicação para Colégio de Aplicação (CA), e também passou a ter a primeira série do segundo ciclo, com os cursos Clássico e Científico. As demais séries do Ensino Médio foram implementadas gradativamente nos anos seguintes. Em 1980, foi acrescentado aos cursos já existentes o Ensino Fundamental com a implementação de oito turmas. Durante esse período os alunos que frequentavam o Colégio eram filhos de professores e servidores técnico-administrativos da Universidade Federal. Em 1992 a partir da Resolução nº 013/CEPE/92, estabeleceu-se que seria três turmas por série e com 25 alunos cada uma, e que o ingresso seria por meio de sorteio aberto para toda comunidade (COLÉGIO DE APLICAÇÃO, 2019).

Inserido no Centro de Ciência da Educação (CED) da Universidade Federal, o CA atende ao ensino fundamental e médio, funciona em prédio próprio, no Campus da Universidade Federal, e segue a política educacional adotada pela mesma e visa atender à trilogia de Ensino, Pesquisa e Extensão (COLÉGIO DE APLICAÇÃO, 2019).

O CA possui um grupo de professores da Educação Especial, que busca atender os estudantes com deficiência, TEA e/ou AH/SD. A entrada de professores da Educação Especial no CA deu-se por meio de ação judicial no ministério da educação movida por pais de alunos com deficiência, no ano de 2014. Nesse mesmo ano abriu-se concurso onde foram efetivadas 14 professoras da Educação Especial.

Das vagas disponíveis para sorteio, está prevista uma cota de 5\% do número de alunos por série para atender este público-alvo da Educação Especial que são os alunos com deficiências, TEA, AH/SD, bem como outros transtornos funcionais específicos. Atualmente são atendidos 55 estudantes desse público-alvo, destes 14 estão no ensino médio. 
Com o trabalho de docência compartilhada, entre os professores das áreas em geral e os professores da Educação Especial, busca-se o trabalho em conjunto no planejamento das atividades a serem aplicadas em sala de aula ou em outros espaços, almejando um ensino colaborativo. As turmas que contemplam a presença de estudantes com deficiência, TEA e/ou AH/SD, dependendo do diagnóstico, poderão contar com um professor da Educação Especial em sala. Este irá desenvolver uma mediação em docência compartilhada nos Anos iniciais do Ensino Fundamental. Já nos Anos Finais do Ensino Fundamental o ensino é colaborativo na docência compartilhada, atendendo os alunos da turma em classe regular e no atendimento educacional especializado (AEE) no contraturno. Mesmo com a presença do professor da Educação Especial em sala, o professor da turma/disciplina deve estar em sala de aula. A distribuição dos professores nas turmas segue alguns critérios que devem estar pautados nas dificuldades de aprendizagem, no comprometimento nas relações sociais, nas atividades do dia a dia, nas barreiras comunicacionais (COLÉGIO DE APLICAÇÃO, 2014).

Para auxiliar os professores da Educação Especial e também os alunos que são atendidos por esses professores, o CA oferece como estágio não obrigatório para alunos das licenciaturas da Universidade Federal uma oportunidade de trabalhar com alunos com deficiência. $\mathrm{O}$ intuito de se ter um bolsista em sala é de contribuir com a melhoria da qualidade do atendimento que é direcionado ao aluno, ao mesmo tempo que contribui com a formação do bolsista.

b. EDUCAÇÃO ESPECIAL NO CURRÍCULO DO CURSO DE LICENCIATURA EM FÍSICA NA UNIVERSIDADE FEDERAL

O curso de Licenciatura em Física iniciou em 1974 dentro do departamento de Física que até então atendia os cursos básicos de formação nas engenharias, juntamente com o Centro de Educação, visando a formação de professores de Física para o ensino médio. Inicialmente, o curso de licenciatura em Física abrangia os conteúdos de Física clássica, introdução à Física moderna e disciplinas básicas relacionadas à educação. Com a criação do curso de bacharelado em 1980, os alunos ingressavam no curso e na metade deveriam optar por um dos dois. Em 1994, os dois cursos foram desmembrados, e o curso de licenciatura passou a ser noturno com 65 vagas (UFSC, 2009).

$\mathrm{Na}$ primeira organização curricular pensada no projeto político pedagógico feito em 2008, é possível perceber que havia apenas uma disciplina direcionada ao ensino inclusivo - Educação e Processos Inclusivos - que seria ofertada na sétima fase. Já as 
demais disciplinas da área da educação traziam uma visão mais geral da educação como um todo.

Analisando o projeto de 2009, onde foram feitas algumas alterações, percebe-se que na sétima fase onde estava a disciplina de Educação e Processos Inclusivos agora existe a disciplina de Língua Brasileira de Sinais. Assim, foi sugerido que a disciplina de Educação e Processos de Inclusão passasse a integrar o quadro de disciplinas optativas. Verificando o currículo atual do curso de licenciatura em Física da Universidade Federal, temos a disciplina de Língua Brasileira de Sinais na sexta fase, e não aparece nenhuma disciplina relacionada à Educação Inclusiva e Educação Especial, nem nas matérias obrigatórias e nem nas optativas (UFSC, 2009, 2019).

Com a análise da elaboração do Projeto Político Pedagógico do curso, é possível perceber que no decorrer da formação o aluno licenciando terá pouco contato com o assunto de Educação Especial e Inclusão. Esse contato vai depender da forma como os professores das disciplinas da educação abordarem esses assuntos, se de forma transversal ou como conteúdo propriamente. Tendo em vista a importância deste tema, acredita-se que maior atenção deveria ser dada e que uma única disciplina não é suficiente para abarcar todas as questões relacionadas à Educação Inclusiva.

\section{METODOLOGIA DA PESQUISA}

Para alcançar os objetivos já descritos, optou-se pela elaboração de dois questionários com questões abertas e discursivas. Um direcionado aos professores da Educação Especial que atuam ou atuaram no Ensino Médio do CA e outro direcionado aos professores de Física também do CA. Os questionários foram elaborados após leituras da Política Nacional de Educação Especial na Perspectiva Inclusiva (Brasil, 2008) e da Proposta Pedagógica de Inclusão Educacional do Colégio de Aplicação da Universidade Federal (COLÉGIO DE APLICAÇÃO, 2014), e também por meio de conversas com professores da área da Educação Especial, incluindo uma conversa destinada à validação das questões elaboradas nos dois questionários.

Primeiro foi elaborada uma série de questões para os dois públicos pelos autores deste trabalho trazendo tópicos considerados importantes. Em seguida, juntamente com uma professora da área da Educação Especial do colégio de aplicação, mas que não se enquadra no público da pesquisa por não atuar no Ensino Médio, foram revisadas as 
questões que tinham sido previamente elaboradas. Feitas as alterações sugeridas pela professora, esta fez a validação dos questionários.

Os questionários foram enviados aos três professores de Física e aos quatro professores da Educação Especial por e-mail, com esclarecimento do que se tratava a pesquisa, incluindo os objetivos almejados. Em anexo o questionário e o termo de consentimento livre esclarecido, convidando-os para a participação desta pesquisa, respondendo ao questionário. Após receber as respostas dos questionários, foi realizada uma análise qualitativa dos dados via metodologia de análise de conteúdo, que consiste em analisar qualitativamente os conteúdos, por meio de um conjunto de técnicas de análise das comunicações (BARDIN, 1994).

Para Bardin (1994), no uso do método de análise de conteúdo, as informações a serem analisadas precisam seguir uma ordem: Inicia-se pela pré-análise, em que é feita uma leitura flutuante para escolhas de documentos; se formula hipóteses e objetivos da pesquisa; elaboração dos indicadores e preparação do material. Depois temos a exploração do material onde se aplica técnicas específicas, e consiste "de operações de codificação, desconto ou enumeração, em função de regras previamente formuladas" (BARDIN, 1994 p. 101). Por último o tratamento dos resultados obtidos (RAMOS; SALVI, 2009). Os resultados foram tratados com vistas ao entendimento da interação entre os professores da área de Educação Especial e os professores de Física, para assim destacar o potencial desta interação para o desenvolvimento de um ensino de Física inclusivo.

\section{ANÁLISE DAS RESPOSTAS DOS PROFESSORES}

Conforme já foi mencionado o questionário foi enviado para quatro professores da Educação Especial que atuam ou atuaram no Ensino Médio do CA, que serão aqui identificadas por PE1, PE2, PE3 e PE4. Todos os professores possuem formação na área, seja em sua primeira graduação ou especialização, mostrando a preocupação do CA em ter profissionais formados na área para melhor atender os alunos com deficiência, buscando sempre a inclusão dos mesmos.

Os docentes da Educação Especial relatam algumas dificuldades em seus trabalhos com professores de outras áreas. A afirmação que mais se destacou foi a de não haver um planejamento antecipado e compartilhado, ou seja, a conversa entre os 
professores de outras áreas com os de Educação Especial não acontece com frequência desejada. Destacam também a falta de compreensão por parte dos professores sobre o que é a inclusão e como deveriam se portar para a sua efetivação. Relatam também que muitos professores das outras áreas consideram que a responsabilidade sobre os estudantes com deficiência é dos professores de Educação Especial, como pode ser visto na asserção abaixo:

PE4 - "Falta compreensão por parte dos docentes, no sentido de que os estudantes com deficiência são da NOSSA responsabilidade, ou seja, os mesmos entendem erroneamente que cabe somente à professora de Educação Especial planejar, elaborar atividades e provas, além da mediação em sala de aula. Esse é um trabalho compartilhado, que envolve parceria e comprometimento de ambas as partes. Essa dificuldade é pouco percebida no Ensino Médio, mas é bem acentuada nos Anos Finais".

Assim, percebe-se que as dificuldades estão relacionadas à falta de percepção de que os professores de Educação Especial não são os únicos responsáveis por esses alunos, mas que estão em sala para mediar o trabalho do professor de outras áreas. No quadro 1 foram destacadas as principais dificuldades encontradas por esses educadores.

Quadro 1 - Dificuldades encontradas ao trabalhar com os professores de outras áreas da educação em salas de aulas.

\begin{tabular}{|l|c|}
\hline Rvista Insianare Categorias & Respostas \\
\hline Realização de planejamento antecipado e compartilhado & 3 \\
\hline $\begin{array}{l}\text { Discordâncias em relação à inclusão (não compreensão) } \\
\text { Erofessores de outras áreas colocam a responsabilidade no Professor da } \\
\text { Educaão Especial }\end{array}$ & 1 \\
\hline
\end{tabular}

Fonte: Os autores, 2019.

O quadro 2 aborda as experiências em relação ao ensino compartilhado e colaborativo com os professores de Física. Em suas falas informam que já tiveram experiências significativas e positivas apesar das dificuldades supracitadas. Em suas asserções reforçam nos professores a falta de tempo e de conhecimento necessário para fazer as flexibilizações e adaptações necessárias. Considerando suas respostas percebese que quando ocorre uma conversa, ou planejamento as experiências são significativas, mas também algumas dificuldades são encontradas, como por exemplo, o pouco tempo para o planejamento e o uso exagerado de aulas muito expositivas, as quais têm se tornado extremamente cansativas. 
Quadro 2 - Experiências sobre ensino colaborativo/compartilhado de Física para os estudantes com deficiência, TEA e/ou AH/SD.

\begin{tabular}{|l|c|}
\hline \multicolumn{1}{|c|}{ Categorias } & Respostas \\
\hline Positiva/Significativa (em alguns casos) & 3 \\
\hline Falta de tempo hábil & 1 \\
\hline $\begin{array}{l}\text { Falta de entendimento do que e como fazer as flexibilizações e } \\
\text { adaptações de material }\end{array}$ & 1 \\
\hline $\begin{array}{l}\text { Adaptação de material tanto pelo professor de Física como do professor } \\
\text { de Educação Especial }\end{array}$ & 2 \\
\hline Aulas expositivas e abstratas & 1 \\
\hline
\end{tabular}

Fonte: Os autores, 2019.

Como todos os professores trabalham no ensino médio, eles também atuam com professores de Física e destacam que é um trabalho em desenvolvimento constante. Por vezes os professores têm dificuldade em compreender as necessidades dos alunos. No entanto, as adaptações são pensadas com atenção buscando compreender a dificuldade dos alunos, o que pode ser visto na asserção a seguir:

PE2 - "Percebo a dificuldade dos professores em perceber as necessidades específicas dos estudantes público-alvo da Educação Especial [...]. Falta de preocupação na adaptação já organizada para o estudante em seu planejamento [...]. Porém, também existem docentes preocupados e que organizam as atividades e somente pedem opinião acerca do que fizeram ao especialista na área".

Nesta fala, percebe-se que há professores preocupados em atender os alunos, e há aqueles que não demonstram essa preocupação, muitas vezes por não terem conhecimento suficiente da área. Os docentes foram questionados sobre o que seria importante na prática dos professores e analisando as respostas é possível perceber que umas das principais preocupações deve ser o planejamento pensado nesses alunos e nas adaptações que devem ser feitas. Que o professor deve ser de todos e para todos os integrantes da sala de aula, demandando um entendimento das necessidades de cada aluno.

Também foram questionados se o colégio consegue suprir as necessidades da inclusão e sobre os aspectos que precisam ser revistos para que a inclusão possa acontecer. Sobre atender as demandas da inclusão destacam que este atendimento está em processo e que possui profissionais capacitados. O quadro 3 mostra as principais 
características trazidas pelos professores para uma boa pratica docente, cabendo destaque à atenção do professor na hora de planejar e adaptar.

Quadro 3 - Considerado importante na prática docente do professor de área quando atua com estudantes com deficiência, TEA e/ou AH/SD

\begin{tabular}{|l|c|}
\hline \multicolumn{1}{|c|}{ Categorias } & Respostas \\
\hline Empatia & 1 \\
\hline Ser professor para todos & 3 \\
\hline Preocupação na hora do planejamento e adaptações & 4 \\
\hline Perceber a necessidade dos alunos & 3 \\
\hline Compreender os alunos como únicos & 1 \\
\hline
\end{tabular}

Fonte: Os autores, 2019.

Os professores da área da Educação Especial também foram questionados sobre os pontos que precisam ser mudados para que a inclusão aconteça. Em suas asserções destacam que os professores precisam se aproximar mais dos estudantes com deficiência para que assim consigam perceber as necessidades de cada um. E na fala de um dos professores é destacado que cada aluno público-alvo da Educação Especial deveria ter um professor da Educação Especial para acompanhá-lo em sala de aula, mas sabe-se que isso é algo aquém da nossa realidade.

PE3 - “[...]. Na minha opinião, para garantir uma inclusão mais efetiva, necessitaria de uma flexibilização na organização e distribuição do trabalho das professoras de Educação Especial, de modo que todos os estudantes público-alvo da Educação Especial, recebessem, além o AEE, também a docência colaborativa em sala de aula com o professor do ensino comum. [...]".

O que seria muito complicado tendo em vista o número de alunos, as demandas da escola e o cenário atual com todos os cortes que a educação vem sofrendo. No quadro 4 foram categorizadas as ações consideradas importantes para que haja um ensino inclusivo. Um ponto que foi bastante destacado é que os planejamentos das disciplinas deveriam ser feitos com antecedência e compartilhado entre os professores de Educação Especial.

Quadro 4 - Tipos de ações em sala de aula consideradas relevantes para o desenvolvimento da aprendizagem para estudantes com deficiência, TEA, AH/SD

\begin{tabular}{|l|c|}
\hline \multicolumn{1}{|c|}{ Categorias } & Respostas \\
\hline Planejamento antecipado, adaptações e flexibilizações dos conteúdos & 4 \\
\hline Aspectos pedagógicos e didáticos para que haja a inclusão & 1 \\
\hline
\end{tabular}




\begin{tabular}{|l|l|}
\hline Aproximação e conhecimento do estudante & 2 \\
\hline Romper barreiras de preconceitos e atitudinais & 1 \\
\hline Procurar o apoio dos professores de Educação Especial & 1 \\
\hline Não subestimar a capacidade dos alunos & 1 \\
\hline
\end{tabular}

Fonte: Os autores, 2019.

Assim, deve haver preocupações com as adaptações e flexibilizações dos conteúdos e atividades. Os professores da área da Educação Especial consideram que para que ocorra inclusão as barreiras atitudinais precisam ser quebradas. Professores precisam se aproximar e entender as necessidades dos alunos e, sempre que preciso, buscar apoio dos professores da Educação Especial.

Os professores da Educação Especial foram questionados sobre o que eles consideram importante para que haja a docência compartilhada de forma efetiva, um ponto elencado por quase todos, e que merece destaque, é que a responsabilidade deve ser tanto do professor da área como do professor de Educação Especial, pois alguns consideram que o aluno é de responsabilidade do professor de Educação Especial.

O planejamento também deve ser algo pensado antecipadamente e sempre que possível, deve ser compartilhado, pois os professores especialistas possuem uma melhor visão do que os estudantes necessitam, e essa questão leva a um dos pontos relatados pelos professores em que o professor da área precisa estar aberto para conversas e sugestões acerca das adaptações e flexibilizações.

Os educadores foram questionados sobre as dificuldades já encontradas enquanto professores da Educação Especial. Analisando as respostas é possível perceber várias experiências, a que foi mencionada mais de uma vez foi relacionada ao fato de que alguns professores de outras áreas não dão aberturas para mudanças que possam ajudar na aprendizagem desses alunos.

Destacam também a dificuldade de se adaptar um conteúdo denso e abstrato, pois muitos desses alunos apresentam grandes dificuldades para a compreensão e para o acompanhamento. A falta de material adequado também foi relatada, pois alguns alunos precisam de um material especifico para conseguir compreender os conteúdos.

PE2 - “[...]. Além disso, o embate ou a falta de empatia do colega professor para como estudante ou outro colega, ausência na abertura para a mudança positiva que beneficie a inclusão e a falta de aproximação com o estudante para ensiná-lo ou 
trabalhar diretamente, deixando para outra pessoa fazê-lo, são algumas das dificuldades encontradas na escola".

Nesta fala, percebe-se que a falta de empatia entre aluno e professor e aluno com algum colega é um ponto que precisa ser trabalhado para que o discente possa se engajar mais e aprender melhor. No quadro 5 estão relacionadas as principais dificuldades.

Quadro 5 - Dificuldades e desafios encontrados em sala de aula com a educação de estudantes com deficiência, TEA e/ou AH/SD

\begin{tabular}{|l|c|}
\hline \multicolumn{1}{|c|}{ Categorias } & Respostas \\
\hline Adaptação de conteúdo denso e abstrato & 1 \\
\hline Falta de Empatia tanto dos professores como dos outros alunos & 1 \\
\hline Sem abertura para mudanças para práticas inclusivas & 2 \\
\hline Barreiras conceituais e atitudinais & 1 \\
\hline Falta de material adequado para se trabalhar em sala & 1 \\
\hline
\end{tabular}

Fonte: Os autores, 2019.

Com a análise das repostas dos professores de Educação Especial é possível perceber que a docência compartilhada entre eles e professores de outras áreas, inclusive os da Física, é algo que está em processo. Algumas barreiras ainda precisam ser quebradas, tanto dos professores como de toda a escola.

Um segundo questionário foi enviado aos professores de Física do CA onde são representados pelas siglas PF1, PF2 e PF3. As respostas foram sintetizadas em quadros buscando categorizar as respostas mais frequentes para que fosse possível ser feita uma análise das mesmas, com o objetivo de compreender o ensino de Física em turmas onde há alunos público-alvo da Educação Especial.

Em relação à formação dos professores de Física, é possível saber que todos possuem formação em licenciatura em Física e mestrado na área de educação científica e tecnológica. Um deles possui doutorado e outro está se doutorando nesta mesma área, o que demonstra que o CA possui profissionais capacitados para o ensino de Física. Além disso, todos trabalham há tempo no colégio e um deles, há 30 anos.

Pensando nos objetivos da pesquisa, perguntou-se aos professores de Física se em sua graduação tiveram alguma disciplina relacionada à Educação Especial, que tratava sobre como trabalhar com os estudantes com deficiência, TEA e ou/ AH/SD, e a resposta foi unânime, não tiveram nenhuma disciplina. 
Ainda em relação à Educação Especial e Inclusiva na formação, questionou-se se em sua caminhada acadêmica, inicial ou continuada, alguma disciplina contribuiu para as práticas inclusivas e todos destacaram que as disciplinas não contribuíram no sentido de mostrar como atender esses alunos especificamente.

PF1 - "Minha formação contribuiu no sentido de apontar para a necessidade de metodologias diferenciadas para que ocorra o aprendizado dos estudantes com necessidade especiais, em função da deficiência. No entanto, minha formação não contribuiu para mostrar como dar conta de desenvolver práticas diferenciadas em uma mesma turma".

O depoimento acima citado destaca que ao longo da formação houve falas no sentido de apontar a necessidade de metodologias diferentes, mas sem avançar no sentido de pensar em como desenvolver tais metodologias. Ou seja, foram discutidos alguns conceitos e estratégias, mas não houve o entendimento dos mecanismos necessários para colocá-los em prática dentro de uma sala de aula.

$\mathrm{O}$ intuito desta pesquisa foi analisar como acontece a docência compartilhada entre os professores de Educação Especial e os professores de Física do CA, ou seja, entender como é este trabalho. A opinião mais frequente foi de que quando o professor da Educação Especial está presente em sala, as adaptações e flexibilizações são melhores organizadas. Também destacam que seguem sugestões sobre as adaptações que precisam ser feitas e como proceder nas avaliações.

Em relação ao planejamento e aulas, alguns afirmam que não há compartilhamento de aulas, e que o planejamento não é compartilhado, eles apenas seguem as sugestões. Com essas respostas percebe-se que mesmo que não seja suficiente, há uma preocupação em fazer adaptações e flexibilizações. No quadro 6 estão elencadas as principais respostas.

Quadro 6 - Como é o trabalho junto dos Professores da Educação Especial.

\begin{tabular}{|l|c|}
\hline \multicolumn{1}{|c|}{ Categorias } & Respostas \\
\hline São feitas sugestões de adaptações e avaliações & 2 \\
\hline Não ocorre o planejamento compartilhado & 2 \\
\hline Não há o compartilhamento das aulas & 2 \\
\hline $\begin{array}{l}\text { Quando há um professor de Educação Especial acompanhando os alunos, } \\
\text { as adaptações são melhores organizadas }\end{array}$ & 3 \\
\hline
\end{tabular}

Fonte: Os autores, 2019. 
Em relação a influência de um estudante com deficiência, TEA e AH/SD nas aulas e nos planejamentos dos professores de Física a resposta mais frequente foi que esses alunos deveriam ser acompanhados pelos professores da Educação Especial, mas que quando isso não é possível, são realizadas mudanças estruturais para que esses alunos possam compreender o conteúdo. Na fala a seguir percebe-se que mesmo com este esforço não conseguem notar uma melhora no aprendizado.

PF2 - “[...]. Quando isso não ocorre faço mudanças estruturais como, por exemplo, escrever com letras maiores, descrever as imagens por meio de desenho no quadro, alterar as avaliações, etc. Todavia, em minha opinião, não ocorre uma melhora efetiva na aprendizagem para os alunos com deficiência. [...]”.

Os professores de Física não consideram adequada a obrigatoriedade de todos os alunos participarem de todas as atividades. Consideram que há atividades que são importantes para turma, mas que para alguns alunos não irá contribuir com a aprendizagem, como é possível perceber na fala a seguir:

PF3 - "A obrigatoriedade, em alguns casos, à participação em todas as atividades a meu ver não é adequada. Selecionar atividades de acordo com o perfil também deveria ser uma opção. Um laboratório, por exemplo, dependendo da atividade pode não ser recomendado".

Com essas asserções, é notável que algumas atividades precisam de adaptações e que nem sempre o aluno vai poder participar de todas as atividades propostas e que essas adaptações podem não contribuir com o aprendizado do aluno.

Em relação às avaliações para os estudantes público-alvo da Educação Especial, os professores relataram que fazem o possível para seguir as orientações dos professores da Educação Especial, fazendo as alterações necessárias. Quando já se sabe das necessidades, algumas mudanças estruturais são feitas, como número de questões, tamanho de fonte, entre outras.

PF3 - "Como citado anteriormente, em um caso com a professora especialista - a mesma que fazia as adaptações - que apesar de não conhecer o conteúdo, tem a experiência para isso. Dessa forma, apresentando-me a tarefa/avaliação e discutindo comigo a forma final. Contudo isso é uma exceção". 
Então, em alguns casos, acontece de o professor de Educação Especial fazer as adaptações e conversar com o professor até chegar a uma versão que seja adequada para o aluno e contemple os conteúdos de Física.

Os professores foram questionados de que forma fazem o planejamento das aulas quando possuem estudantes com deficiência, TEA, AH/SD, e analisando as respostas, percebe-se que todos fazem os planejamentos para a turma como um todo e depois fazem as alterações e adaptações que são necessárias, seguindo orientações dos professores da Educação Especial.

No quadro 7 foram categorizadas as respostas em relação ao que os professores de Física consideram importantes no processo de ensino-aprendizagem de Física, sempre contemplando os alunos da Educação Especial, havendo três relatos diferentes: que é necessário que o professor possua conhecimento para o uso de tecnologias e metodologias que possam atender as necessidades destes alunos; que o trabalho em conjunto com o professor da Educação Especial deve acontecer para que consigam entender e atender as demandas que surgem; e que é necessário o foco nos conceitos relacionados ao cotidiano do aluno, trazendo a Física e inserindo-a o mais próximo possível à realidade desse aluno.

Quadro 7 - O que você considera que deva ser levado em consideração no processo de ensinoaprendizagem de Física para a formação de estudantes com deficiência, TEA e/ou AH/SD?

\begin{tabular}{|l|c|}
\hline Conista Categorias & Respostas \\
\hline Conhecimento adquirido para uso de tecnologias e metodologias & 1 \\
\hline Trabalho junto do professor de Educação Especial & 1 \\
\hline Conceitos relacionados a prática cotidiana dos estudantes & 1 \\
\hline
\end{tabular}

Fonte: Os autores, 2019.

Os professores foram questionados sobre dificuldades e desafios já encontrados quando trabalharam com alunos da Educação Especial. Afirmaram que uma das dificuldades é a falta de conhecimento da área de Educação Especial, pois em suas formações esse assunto não foi abordado de forma significativa. Levando em conta que em suas turmas há em torno de 25 alunos, eles consideram que não há tempo suficiente, em sala de aula, para que possam atender adequadamente todos os alunos. E um deles acredita que nem todas as atividades propostas precisariam ser realizadas pelos alunos da Educação Especial. 
Com as respostas dos professores de Física percebe-se que a inclusão desses alunos ainda está em processo, que a falta de conhecimento da área é uma dificuldade que precisa ser superada para que as necessidades dos alunos possam ser atendidas. Que a docência compartilhada na maioria das vezes não acontece. E que quando se fala em inclusão deve-se deixar claro que os estudantes possuem seus direitos como também seus deveres.

Para Rigo (2018), a cultura escolar e a formação dos professores, em geral, nunca levaram em consideração as diferenças na escola, constituindo-se assim como um espaço normalizador de condutas. Para a autora residem aí as dificuldades em transformar a escola em um espaço inclusivo para todos. De todo modo, a inclusão nas escolas brasileiras é um processo que está em construção e precisa ter sua presença garantida nos cursos de formação docente para que o professor possa saber o que fazer quando tiver alunos com deficiência em suas aulas. Esta presença pode ser garantida em disciplinas específicas da área da Educação Especial, mas isso não é suficiente. É importante que estas questões cheguem a outras disciplinas, como as de Metodologia de Ensino, Prática de Ensino e de Estágio Supervisionado.

Além disso, Nascimento et al (2017), enfatizam a urgência de uma formação continuada, que seja eficaz em relação aos princípios da inclusão, visando assim a superação de práticas pedagógicas excludentes e/ou negligentes no que tange a uma educação de boa qualidade.

\section{CONSIDERAÇÕES FINAIS}

Durante a elaboração deste trabalho percebeu-se que a docência compartilhada entre professores de Física e os da Educação Especial, ou seja, o ensino inclusivo nas turmas onde há alunos do público-alvo da Educação Especial, está em processo e alguns obstáculos precisam ser superados, mesmo o CA contando com a presença de profissionais qualificados na área.

As asserções das profissionais da área da Educação Especial, mostra que deve haver uma aproximação dos professores com esses alunos, e também entre os próprios alunos, para que o professor possa compreender melhor a necessidade de cada um. Segundo Cruz e Libardi (2017, p. 7) "[...] discussões devem ser incentivadas, não apenas entre o professor e o estudante, mas também, com os demais colegas de classe, promovendo assim, não somente a inclusão didática, mais também a social”. 
Sabe-se que nem sempre há tempo hábil para isso, como foi relatado pelos professores de Física e também pelos próprios professores da Educação Especial, mas é um ponto que demanda mais atenção por parte de todos os sujeitos envolvidos com o processo de ensino-aprendizagem.

Conforme visto nas falas dos professores da Educação Especial percebe-se que a docência compartilhada dificilmente acontece e o planejamento antecipado e compartilhado é outro ponto destacado que está em processo. O que acontece, geralmente, é que os professores das outras áreas seguem as sugestões dos professores da Educação Especial, como se fosse uma receita de bolo.

Há também a questão de transferência de responsabilidade. Quando há um professor da Educação Especial junto ao aluno, é preciso entender que esse professor está em sala para mediar, para ajudar no aprendizado do aluno e não para ser o professor exclusivo do aluno. Este, por sua vez, deve ser de toda a turma, tomando para si a responsabilidade de alcançar a todos.

Um dos Professores da Educação Especial traz em sua fala que o ideal seria que todos os estudantes do público-alvo da Educação Especial deveriam ter um professor os acompanhando, mas sabemos que isso é algo quase que utópico, principalmente com a atual situação da educação no Brasil, onde cortes orçamentários e ações públicas limitadas e a falta de conhecimento de algumas famílias desses alunos acontecem constantemente.

Como visto nas falas dos professores de Física, percebe-se que não houve em suas formações disciplinas que contribuíssem para que pudessem atender os alunos públicoalvo da Educação Especial, e assim buscam seguir as orientações dos professores especializados na área para fazer as adaptações e flexibilizações necessárias. Além disso, afirmam que quando há um professor especialista em sala as adaptações são melhores organizadas contribuindo mais para que o aluno possa compreender os conteúdos.

Assim para que haja no futuro um ensino de Física adequado para turmas com estudantes do público-alvo da Educação Especial é necessário a presença efetiva do tema nas disciplinas que possuem compromisso com a formação docente, não só na licenciatura em Física, mas em todas as demais licenciaturas, buscando mostrar as metodologias que possam contribuir com o aprendizado dos alunos como também diferentes maneiras de utilizar essas metodologias, com diferentes recursos, para que os professores possam suprir as demandas enfrentadas na prática. 
Com relação a este ponto, Bozelli e Santos (2015) destacam a formação inicial de professores não deve ser apenas com inclusão de algumas disciplinas específicas, mas uma formação que englobe os princípios da inclusão.

Reforçando, segundo Araújo, Oliveira e Lima (2017, p. 6):

\begin{abstract}
São muitos os desafios a serem enfrentados na inclusão, mas as iniciativas e as alternativas realizadas pelos educadores são essenciais no aprendizado, mesmo que não apresente números consideráveis, a inclusão tem sido admitida e revela ações que devem ser consideradas práticas para apoiar o professor em pleno exercício. Ter um segundo professor em sala, é um exemplo a ser seguido, pois há a necessidade de se ter presente durante todas as aulas ou em alguns momentos, nas mais diversas modalidades, seja como intérprete, apoio, monitor ou auxiliar, já seria uma grande ajuda, esse professor poderá possuir formação específica, a participação do professor do Atendimento Educacional Especializado (AEE) poderá ocorrer na realização do planejamento e no suporte quanto à compreensão das condições de aprendizagem dos alunos, como forma de auxiliar a equipe pedagógica.
\end{abstract}

Assim percebe-se que há muito o que melhorar no que diz respeito ao ensino de Física para estudantes da Educação Especial, pois mesmo havendo preocupações, ainda há um longo caminho a ser percorrido. Neste sentido, para que ocorra a inclusão, faz-se necessário um entendimento tanto dos professores como de toda a organização escolar em como acolher e pôr em prática o ensino a esses alunos, efetivando um trabalho árduo que vem sendo construindo e adaptado ao longo de várias décadas.

\title{
6. REFERÊNCIAS
}

ARAÚJO, L. S. C., OLIVEIRA, R. S, LIMA, G. M. C. O., Ensino de Física na Perspectiva da Educação Inclusiva. In: Anais: XXII Simpósio Nacional de Ensino de Física, SNEF 2017, São Carlos-SP. Disponível em: $<$ http://www.sbf1.sbfisica.org.br/eventos/snef/xxii/sys/resumos/T1055-1.pdf > acesso em abr 2020.

BARDIN, L. Análise de conteúdo. Lisboa: Edições 70, 1994.

BOZELLI, F. C., SANTOS, J. A. Inclusão e formação de professores: que apontamentos emergem dessa relação por futuros professores de física? In Anais: X ENPEC - Encontro Nacional de Pesquisa em Educação em Ciências, Águas de Lindóia/SP 2015. Disponível em: <http://www.abrapecnet.org.br/enpec/xenpec/anais2015/resumos/R2003-1.PDF> acesso em abr 2020.

BRASIL. Secretaria de Educação Especial. Política Nacional de Educação Especial na Perspectiva da Educação Inclusiva. Brasília, DF, jan. 2008a. [Documento elaborado pelo Grupo de Trabalho nomeado pela portaria n. 555/2007, prorrogada pela portaria $\mathrm{n}$. 948/2007, entregue ao ministro da Educação em 7 de janeiro de 2008]. Disponível em: <http://portal.mec.gov.br/arquivos/pdf/politicaeducespecial.pdf> Acesso em: dez 2018. 
CAMARGO, E. P. NARDI, R.; VERASZTO, E. V. A comunicação como barreira à inclusão de alunos com deficiência visual em aulas de óptica. Revista brasileira de Ensino de Física, v. 30, n. 3, p. 3401.1-3401.13, 2008. Disponível em:

<http://www.scielo.br/pdf/rbef/v30n3/3401.pdf> acesso em abr 2020

\section{COLÉGIO DE APLICAÇÃO. Proposta Pedagógica De Inclusão Educacional Do} Colégio De Aplicação/UFSC. 2014. Disponível em:

<http://www.ca.ufsc.br/files/2015/04/Porposta_Pedagogica_Inclusao_CA_2014.pdf> acesso em abr. 2019.

COLÉGIO DE APLICAÇÃO. Histórico do CA. Disponível em:

$<$ http://www.ca.ufsc.br/historico-do-ca/> acesso em maio de 2019.

CRUZ, I. A. LIBARDI, H. Concepções de uma licencianda em física: obstáculos para o ensino- aprendizagem dos estudantes com deficiência auditiva. Atas do Simpósio Nacional de Ensino de Física. São Carlos, 2017. Disponível em: <http://www.sbf1.sbfisica.org.br/eventos/snef/xxii/sys/resumos/T0734-2.pdf> acesso em abr 2020.

MAZZOTTA, M. J. S. Evolução da educação especial e as tendências da formação de professores de excepcionais no Estado de São Paulo. Tese de Doutorado. Faculdade de Educação Universidade de São Paulo, São Paulo, SP. 1989.

NASCIMENTO, W. R. S.; CHAHINI, T. H. C.; NETO, A. P. A Necessidade de Metodologias Inclusivas no Processo Ensino-Aprendizagem de Física aos Discentes com Deficiência Visual. Atas do Simpósio Nacional de Ensino de Física. São Carlos, 2017. Disponível em:

<http://www.sbf1.sbfisica.org.br/eventos/snef/xxii/sys/resumos/T0694-1.pdf> acesso em abr 2020.

RAMOS, R.C. S. S.; SALVI, R. F. Análise de conteúdo e análise do discurso em Educação Matemática: um olhar sobre a produção em periódicos qualis A1 e A2. In: Seminário Internacional de Pesquisa em Educação Matemática, 4, 2009, Brasília, Atas... Brasília: SBEM, 2009. p. 01-20. Disponível em: <http://www.uel.br/grupopesquisa/ifhiecem/arquivos/9GT94689598053.pdf> acesso em: junho 2019.

RIGO, N. M. O dispositivo da inclusão escolar e a produção de subjetividades. Revista Insignare Scientia-RIS, v. 1, n. 3, 2018. Disponível em: <https://periodicos.uffs.edu.br/index.php/RIS/article/view/10616> acesso em: abr.2020.

SILVA, C. O. ALENCAR, D. N. F. OLIVEIRA, V. O. C. C. ARAÚJO, R. C. S. S. CASTRO, P. A. A evolução da educação especial no brasil: pontos e passos. In: iii 
congresso nacional de educação, 2016, Natal. Inclusão, direitos humanos e interculturalidade. Campina grande: realize, 2016. Disponível em: <http://www.editorarealize.com.br/revistas/conedu/trabalhos/TRABALHO_EV056_M D1_SA14_ID1304_11082016230920.pdf> acesso em: ago 2019.

TANNUS-VALADAO, G.; MENDES, E. G. Inclusão escolar e o planejamento educacional individualizado: estudo comparativo sobre práticas de planejamento em diferentes países. Rev. Bras. Educ., Rio de Janeiro, v. 23, e230076, 2018. Disponível em: <http://www.scielo.br/scielo.php?script=sci_arttext\&pid=S1413-

$24782018000100261 \& \operatorname{lng}=$ pt\&nrm=iso $>$ acessos em maio 2019.

UNIVERSIDADE FEDERAL DE SANTA CATARINA. Projeto pedagógico do curso: parte 1. 2009. Disponível em: <https://fisica.paginas.ufsc.br/files/2015/08/PPCLic-Fisica-20091-Parte1.pdf> acesso em ago 2019.

UNIVERSIDADE FEDERAL DE SANTA CATARINA. Projeto pedagógico do curso: parte 2. 2009. Disponível em: <https://fisica.paginas.ufsc.br/files/2015/08/PPCLic-Fisica-20091-Parte2.pdf > acesso em ago 2019.

UNIVERSIDADE FEDERAL DE SANTA CATARINA. Projeto pedagógico do curso: parte 3. 2009. Disponível em: <https://fisica.paginas.ufsc.br/files/2015/08/PPCLic-Fisica-20091-Parte3.pdf> acesso em ago 2019.

UNIVERSIDADE FEDERAL DE SANTA CATARINA. Projeto pedagógico do curso: parte 4. 2009. Disponível em: <https://fisica.paginas.ufsc.br/files/2015/08/PPCLic-Fisica-20091-Parte4.pdf> acesso em ago 2019.

UNIVERSIDADE FEDERAL DE SANTA CATARINA. Currículo do curso de licenciatura em Física. 2019. Disponível em:

$<$ https://cagr.sistemas.ufsc.br/relatorios/curriculoCurso?curso=225> acesso em ago 2019. 